\title{
SENSORY CONTRIBUTION FROM EXTRACTS OF BOTANICALS TO DISTILLED ALCOHOLIC BEVERAGES
}

\author{
W. M. M. S. U. WIJEYARATNA \\ State Distilleries Corporation, Kandy, Sri Lanka.
}

AND

U. SAMARAJEEWA AND R. O. THATTIL

Postgraduate Institute of Agriculture, University of Peradeniya, Peradeniya, Sri.Lanka.

(Date of receipt: 19 July 1988)

(Date of acceptance: 11 January 1989)

\begin{abstract}
Extracts from botanicals were examined by sensory evaluation for their ability to improve the flavour of $15 \%$ aqueous ethanol as an alcoholic beverage. More than $75 \%$ of the $35 \%$ agneous sthanol extractable constituents were extracted from the powdered botanicals on refluxing in Soxhlet for $2 \mathrm{~h}$. The extracts from cloves, cinnamon, "ingurupiyali", ginger, cardomum, nutmeg and mace improved the flavour of $15 \%$ aqueous ethanol at concentrations of $8.2,1.9,3.3,6.7,2.5,22.5$, and $26.3 \mathrm{ppm}$ respectively. The extracts of cummin seeds, coffce beans and pepper did not contribute positively to flavour of $15 \%$ aqueous ethanol at their most acceptable concentrations. The extracts of coriander, dill seed, fcnugreek, mustard and "valmee" did not contribute a regular flavour pattern when assessed at a series of concentration and hence were eliminated. Cinnamon, cloves and cardomum provided the most preferred flavour contributions individually as well as in combinations of two at a time, at several concentracions.
\end{abstract}

\section{Introduction}

Flavouring of aqueous ethanol (spirits) with botanicals is practised to produce alcoholic beverages in the liquor industries today, avoiding the maturation treatment. In Sri Lanka, the production of alcoholic beverages from silent spirits is expanding in view of the decline in production of spirits from fermented palm saps, cóconut (Cocos nucifera L.) and palmyrah (Borassus flabellifer L.).

In this study extracts from locally available botanicals were added to silent spirits. The concentrations at which the extracts from botanicals rendered the spirits more acceptable, and their presence recognized were established by a sensory evaluation panel.

The order of preference of individual and combined botanicals, that rendered the spirits most acceptable was established.

\section{Materials and Methods}

\subsection{Botanicals}

The botanicals cardomum (Elettaria cardomomum), cinnamon bark (Cinnamomum zeylanicum), clove buds (Syzyngium aromaticum), coffee bean 
(Coffea arabica), coriander seed (Coriandrum sativum), cummin seed (Cuminum cyminum), dill. seed (Anethum graveolens), fenugreek (Trigonella foenum graceum), ginger (Zingiber officinale), "ingurupiyali" (Kaempferia galanga), mace and kernel of nutmeg (Myristica fragrans) mustard seed (Brassica juncea), black pepper (Piper nigrum) and stems of "valmee" (Glycorrhiza glabra.) were used to extract flavour constituents.

\subsection{Test Soluticns}

The ethanol test solutions were prepared by diluting potable spirit containing $96 \%(\mathrm{v} / \mathrm{v})$ ethanol with glass distilled water to $35 \%$ ethanol for the extraction of botanicals and $15 \%$ ethanol for sensory evaluation. All test samples were brought to the same colour by adding caramel. The potable spirits used in this study was purchased from State Sugar Corporation, Kantalai. The GLC trace of the spirits on a BP 20 capillary column and flame ionization detector gave only one peak (ethanol) and the estimated purity was $100 \%$.

\subsection{Sensory Evaluation}

Pañel: From a pool of 100 volunteers employed at the State Distilleries Corporation, Kandy, 30 volunteers were selected based on their ability to judge alcoholic beverages as examined by "Tringle Test" and the "Duo- trio test". 1 "These volunteers who formed the panel were divided into 6 groups, so that each group consisted of sensory evaluators of different age, health status, education, smoking habits, type of employment and living area.

In sensory evaluation, the judges of the panel were required to rank the samples in a 'hedonic scale' indicating their preferences as : 1-like extremely : 2-like very much : 3-like moderately : 4-like slightly : 5-neither like nor dislike : 6 -dislike slightly : 7-dislike moderately : 8-dislike very much and.9-dislike extremely. The duplicate and triplicate samples submitted in the preliminary experiments showed up to $5 \%$ variations in judgements.

All sensory evaluation experiments were carried out in late mornings, between $9.00 \mathrm{a} . \mathrm{m}$. to $11.00 \mathrm{a} . \mathrm{m}$. and early evenings, between $2.00 \mathrm{p} . \mathrm{m}$. to 3.30 p.m. on week days avoiding Monday mornings and Friday evenings. Samples were served in clean $50 \mathrm{ml}$ clear glasses of the same type, in a quiet room with comfortable seats, artificial lighting from fluorescent tubes and containing air free from destructive odours. Between 6-9 samples were tested by a judge in a given sitting. Boiled water and facilities were provided to rinse the mouth prior to tasting each sample.

\subsection{Extraction of Flavour Constituents from Botanicals}

The botanicals were ground to pass through $500 \mathrm{~m} \mu$ sieve, in a Stein mill model $\mathrm{M}-2$ for $3 \mathrm{~min}$. at a speed of 7 . The moisture was estimated by drying $1 \mathrm{~g}$ samples at $105^{\circ} \mathrm{C}$ for $2 \mathrm{~h}^{3}$ The powdered botanicals equivalent to $5 \mathrm{~g}$ on dry weight basis, were extracted with $100 \mathrm{ml} 35 \%$ aqueous ethanol in 
Soxhlet at a siphon rate of $8-10$ cycles per $h$ for 1 h. The residue was reextracted thrice under similar conditions. A fraction from each extract.(10 $\mathrm{ml}$ ) was evaporated to dryness over a water bath and then in a vacuum oven at $70^{\circ} \mathrm{C}$ to estimate the dry weight.

Solutions of botanical extracts were prepared by pooling the Soxhlet extracts from first and second extractions and making to $200 \mathrm{mi}$ with $35 \%$ aqueous ethanol. The resulting solutions, were dilutec 10 fold with $35 \%$ aqueous ethanol and stored at $4^{\circ} \mathrm{C}$ pending evaluation.

\subsection{Establishment of Unpleasant and Detection Thresholds}

A series of test samples of $15 \%$ ethanol containing the extracts of each of the botanicals in the order of increasing concentration was submitted to the judges in the six groups to assess the ccncentrations of individual botanicals at which the spirits become unpleasant and the concentration at which the added botanical could be identified. (The botanical used was not disclosed to the judges). The concentration at which $50 \%$ of the judges assessed spirits as unpleasant: was established as unpleasant threshold. The concentration at which $50 \%$ of the judges identified the added botanica. correctly was established as the detection threshold.

\subsection{Establishment of Most Acceptable Concentrations}

A series of nine samples for each of the botanicals, within the range decided by the unpleasant threshold and by the preliminary experimerts, was submitted to the judges for ranking in the nine point hedonic scale. The samples submitted, randomized among and within the groups were coded using numbers or letters following no specific sequence. Histograms were prepared for each of the rank (1-9) and for each botanical by plotting the number of judges giving the rank against the concentration of the botanical. The most acceptable concentration was established as the concentration preferred by the highest number of judges from the mode of the frequency distribution.

\subsection{Statistical Analysis}

Non-parametric techniques were used for the analysis of data as application of parametric proceedures of analysis would not be valid for data based on ranks. The setting up oî this study was a randomized complete block where the judges were taken as blocks and the botanical extracts as treatments. The overall significant differences among the treatments were assessed by Friedman's test. ${ }^{2}$ In establishing the most acceptable concentrations of botanicals the data were analysed using Wilcoxon rank-sum test for comparisons in pairs. ${ }^{2}$ 


\subsection{Comparison of Botanicals for Order of Acceptability at.Their Most Acceptable Concentrations}

The ethanol test solutions flavoured with individual botanicals at their most acceptable concentration were compared together with $15 \%$ ethanol containing no extracts and the order of preference was established based on the ranking by the judges in the nine point hedonic scale.

A second set of ethanol test solutions containing a combination of extracts from two botanicals at a time, each contributing $50 \%$ of the most acceptable concentration was prepared. The 45 different combinations of test solutions grouped into five sets were initially ranked by the judges in the hedonic scale. The most acceptable combination of extracts in the test solutions from each of these sets were next ranked together in a six point hedonic scale by the judges to select the order of preference.

A third set of ethanol test solutions containing a combination of extracts from two botanicals at a time, one contributing $25 \%$ of it's most acceptable concentration and the other contributing $75 \%$ of it's most acceptable concentration was prepared. The ninety combinations produced were grouped into 10 sets for ranking as before. The most acceptable two samples for each set, together with a control of $15 \%$ ethanol (total of 21 combinations) was divided into 3 groups of 7 each and ranked by judges in a seven point hedonic scale. The final order of preference was established based on ranking by the judges in these 3 stages.

\subsection{Overall Order of Preference of Botanicals}

The overall order of preference of botanical extracts in $15 \%$ ethanol solution was established by ranking the most acceptable two samples from each of the above sets, containing the individual botanicals extracts, combination of extracts from two botanicals at $50 \%$ most acceptable concentration and the combination of extracts from two botanicals at $25 \%$ and $75 \%$ most acceptable concentrations. The ranking by the judges was done in a seven point hedonic scale.

\section{Results and Discussion}

\subsection{Extraction of Flavour Constituents}

Aqueous ethanol (35\%) was used in extracting the botanicals as the extracted material should be totally soluble giving a clear liquid at the marketstrength of spirits. It was found, that $85 \%$ of the aqueous ethanol extractable material could be obtained by extracting in Soxhlet for $2 \mathrm{~h}$. except in case of ginger where only $70 \%$ was extracted. The extraction for $2 \mathrm{~h}$ in Soxhlet was therefore fixed as the standard. The botanicals used for extraction contained less than 10\% moisture except for "valmee"(Table 1). 
Table 1. The moisture percentage and the concentrations at which the botanical extracts are detectable, unpleasant and most acceptable in $15 \%$ ethanol.

\begin{tabular}{|c|c|c|c|c|}
\hline \multirow[t]{2}{*}{ botanical } & \multirow{2}{*}{$\begin{array}{l}\text { moisture } \\
\text { percentage }\end{array}$} & \multicolumn{3}{|c|}{ thresholds ( $\mathrm{mg}$ extract/l) } \\
\hline & & detection & unpleasant & most acceptable \\
\hline cardomum & 8.6 & 5.10 & 4.68 & 2.55 \\
\hline cinnamon & 7.3 & 4.75 & 3.33 & 1.90 \\
\hline cloves & 5.5 & 11.28 & 10.25 & 8.20 \\
\hline coffee bean & 8.3 & $16: 80$ & 14.40 & 12.00 \\
\hline coriander & 7.5 & 1.68 & 0.56 & 0.00 \\
\hline cummin seed & 6.4 & 8.05 & 4.60 & 3.45 \\
\hline dill sced & 6.4 & 2.59 & 0.93 & 0.00 \\
\hline fenugreek & 4.9 & 3.78 & 0.54 & 0.00 \\
\hline ginger & 14.8 & 8.55 & 9.50 & 6.65 \\
\hline "ingurupiyali" & 9.8 & 5.80 & 4.71 & 3.26 \\
\hline mace & 3.8 & n. i. & 30.63 & 26.25 \\
\hline mustard & 6.5 & 2.21 & -0.98 & 0.00 \\
\hline nutmeg & 4.8 & 28.13 & 26.25 & 22.50 \\
\hline pepper seed & 5.9 & 4.39 & 3.04 & 2.03 \\
\hline "valmee" & 10.9 & 3.31 & 2.04 & 0.00 \\
\hline
\end{tabular}

n. i. - not identifyable up to $70 \mathrm{mig} / \mathrm{l}$

In establishing the sensory evaluation panel reliability was achieved as far as possible by eliminating those who failed to detect flavour differences when tested by "Triangle" and "Duo-trio" tests. The uniformity and wide range of sensory responses was maintained by grouping the judges so that each group contained people of diverse habits.

\subsection{Unpleasant and Detection Thresholds}

The botanical extracts in test solutions could contribute a decoction-likeflavour to the spirits at certain concentrations causing a disadvantage. The recognition of the botanical added to improve the flavour may sometimes 
devalue the product and discourage the consumer. The concentrations at which these features would become obvious was establised by sensory evaluation (Table 1). It is noteworthy that the concentration at which the flavoured test solutions could be detected was higher than the concentrations at which the presence of flavour constituent from the botanicals render the test solutions unpleasant except in case of ginger.

\subsection{Most Acceptable Concentrations}

Of the extracts from the 15 botanicals examined, the test solutions flavoured with coriander, dill seed, fenugreek, mustard and "valmee" did not show a normal distribution pattern when the number of judges giving any given rank was plotted against the concentration. They were eliminated from further tests as their most acceptable concentration cannot be established (Table 1). Of the extracts from the balance 10 botanicals evaluated cloves, cinnamon, "ingurupiyali", ginger, cardomum, nutmeg and mace were judged to improve the flavour of $15 \%$ ethanol at their most acceptable concentrations, with cloves and cinnamon providing the best flavours (Table 2).

Table 2. The decrease in order of acceptability of extracts from individual botanicals in $15 \%$ ethanol and their most acceptable concentrations. (mg extract/l).

\begin{tabular}{lc}
\hline $\begin{array}{c}\text { botanical } \\
\text { (in decreasing order of } \\
\text { acceptabilicy) }\end{array}$ & $\begin{array}{c}\text { most acceptable } \\
\text { concentration }\end{array}$ \\
\hline cloves & 8.2 \\
cinnamon & 1.9 \\
"ingurupiyali" & 3.3 \\
ginger & 6.7 \\
cardomum & 2.5 \\
nutmeg & 22.5 \\
mace & 26.3 \\
15\% ethanol (control) & 3.5 \\
cummin seed & 12.0 \\
coffee bean & 2.0 \\
\hline pepper &
\end{tabular}


Of the 45 combinations of spirits obtained by combining extracts from two botanicals at a time, at $50 \%$ of their most acceptable concentrations, only 5 combinations contributed to the flavour of $15 \%$ ethanol positively (Table 3). Cardomum, cinnamon and cloves between themselves were judged to provide the most preferred combinations.

Table 3. The decrease in order of acceptability of combination of extracts from botanicals at $50 \%$ of their most acceptable concentration. (mg extract / l)

\begin{tabular}{|c|c|c|c|}
\hline \multicolumn{2}{|c|}{ botanicals } & \multicolumn{2}{|c|}{ concentration } \\
\hline $\mathrm{A}$ & $\overline{\mathrm{B}}$ & $\mathrm{A}$ & $\bar{B}$ \\
\hline cardomum & cinnamon & 1.25 & 0.95 \\
\hline cinnamon & cloves & 0.95 & 4.10 \\
\hline "ingurupiyali" & ginger & 1.63 & 3.33 \\
\hline coffee & "ingurupiyali" & 6.00 & 1.63 \\
\hline cloves & "ingurupiyali" & 4.10 & 1.63 \\
\hline $15 \%$ ethanol & - & - & - \\
\hline
\end{tabular}

Of the 90 possible combinations evaluated as combined extracts from two botanicals, $w$ one contributing at $25 \%$ of its most acceptable concentration, and the other contributing at $75 \%$ of the most acceptable concentration, 19 combinations were judged to provide a better flavour than the control, $15 \%$ ethanol (Table 4). Combinations oî cloves, cinnamon and cardomum between themselves were judged to be the best. Extracts from these three botanicals appeared to occur more frequently in combination with others in the 19 more preferred combinations. 
Table 4. The decrease in order of acceptability of combinations of extracts from botanicals at $25 \%$ (A) and $75 \%(B)$ of their most acceptable concentrations ( $m$ extract / 1 ).

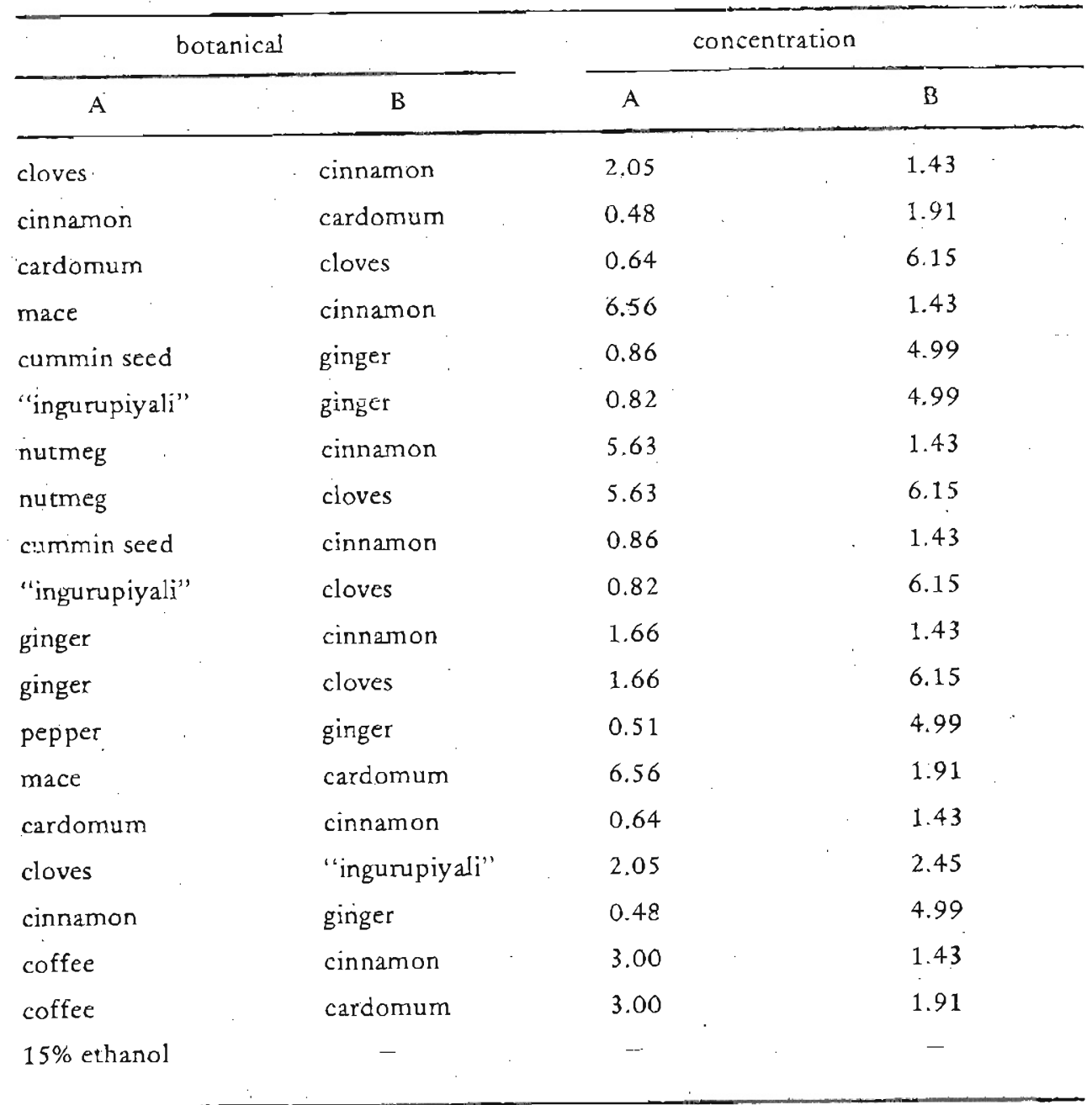

\subsection{Overall Freference of Added Botanical Extracts}

When the two most acceptable botanicals or combinations of botanicals from each of the above sets (Tables 2, 3 and 4) were compared, combination of cloves and cinnamon was judged the best (Table 5 ). It is noteworthy that in all experiments the extracts from the botanicals cloves, cinnamon and cardomum were judged to make the best contributions towards flavour individually as well as in the two different combinations examined. 
mable 5. The most acceptable concentrations of extracts from individual botanicals and combinations of botanicals arranged in the decreasing order in $15 \%$ ethanol.

\begin{tabular}{|c|c|c|c|}
\hline \multicolumn{2}{|c|}{ botanicals } & \multicolumn{2}{|c|}{ concentration (mg $/ \mathrm{l}$ ) } \\
\hline A & B & A & B \\
\hline cloves & cinnamon & 2.05 & 1.43 \\
\hline cinnamon & cardomum & 0.48 & 1.91 \\
\hline cinnamon & cloves & 0.95 & 4.10 \\
\hline cardomum & cinnamon & 1.28 & 0.95 \\
\hline cinnamon & - & 1.90 & - \\
\hline cloves & - & 8.20 & - \\
\hline $15 \%$ ethanol & - & - & - \\
\hline
\end{tabular}

\section{Conclusion}

Dxtracts from cloves, cinnamon and cardomum could be, used in impioving the flavour characteristics of silent spirits to produce a processed alcoholic beverage more acceptab!e than the beverages produced by using the spirits alone.

\section{Acknowledgement}

The authors acknowledge with gratitude the valuable contribution of the employees of the State Distilleries Corporation, Kandy, to this study by voluntarily serving in the panel of judges.

\section{References}

1. CHARLEY, T. (1978) J. Food Sci. $43: 143$

2. LEHMANN, E. L. (1975) Nonparametrics. Holden -Day, Inc, San Fransisco.

3. PEARSON, D. (1976) The chemical analysis of foods. 7th Ed: 6: Chemical publishing Co., Inc., New York. 